\title{
Experience with Palladium Diffusers in Tritium Processing
}

$$
\text { Conf }-950506-3 \text {. }
$$

by

T. Motyka

Westinghouse Savannah River Company

Savannah River.Site

Aiken, South Carolina 29808

E. A. Clark

D. A. Dauchess

$L K$ Houng

R. L Rabum

A document prepared for FIFTH TOPICAL MEETING ON TRITIUM TECHNOLOGY IN FISSION, FUSION, AND ISTOPIC APPLICATIONS at Lake Maggiore from 05/28/95 - 06/03/95.

\section{DOE Contract No. DE-AC09-89SR18035}

This paper was prepared in connection with work done under the above contract number with the U.S.

Department of Energy. By acceptance of this paper, the publisher and/or recipient acknowledges the U.S.

Government's right to retain a nonexclusive, royalty-free license in and to any copyright covering this paper, along with the right to reproduce and to authorize others to reproduce all or part of the copyrighted paper. 


\section{DISCLAIMER}

This report was prepared as an account of work sponsored by an agency of the United States Government. Neither the United States Government nor any agency thereof, nor any of their employees, makes any warranty, express or implied, or assumes any legal liability or responsibility for the accuracy, completeness, or usefulness of any information, apparatus, product, or process disclosed, or represents that its use would not infringe privately owned rights. Reference herein to any specific commercial product, process, or service by trade name, trademark, manufacturer, or otherwise does not necessarily constitute or imply its endorsement, recommendation, or favoring by the United States Government or any agency thereof. The views and opinions of authors expressed herein do not necessarily state or reflect those of the United States Government or any agency thereof.

This report has been reproduced directly from the best available copy.

Available to DOE and DOE contractors from the Office of Scientific and Technical Information, P.O. Box 62, Oak Ridge, TN 37831; prices available from (615) 576-8401.

Available to the public from the National Technical Information Service, U.S. Department of Commerce; 5285 Port Royal Road, Springfield, VA 22161. 


\section{DISCLAIMER}

Portions of this document may be illegible in electronic image products. Images are produced from the best available original document. 


\section{EXPERIENCE WITH PALLADIUM DIFFUSERS IN TRITIUM PROCESSING (U)}

E. A. Clark, D. A. Dauchess, L. K. Heung, R. L. Rabun, T. Motyka

Westinghouse Savannah River Company

Savannah River Site

Aiken, South Carolina 29808

January 27, 1995

A paper proposed for presentation

Fifth Topical Meeting on Tritium Technology in Fission, Fusion, and Isotopic Applications

Lake Maggiore, Italy

28 May-3 June 1995

and for publication in the proceedings

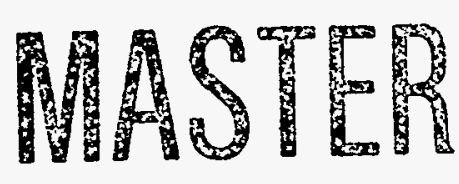

* This article was prepared in connection with work done under Contract No. DE-AC09$89 S R 18035$ with the US Department of energy. By acceptance of this article, the publisher and/or recipient acknowledges the US Government's right to retain a non-exclusive, royalty-free license in and to copyright covering this article, along with the right to reproduce and to authorize others to reproduce all or part of the copyrighted article. 


\title{
EXPERIENCE WITH PALLADIUM DIFFUSERS IN TRITIUM PROCESSING
}

\author{
E. A. Clark, D. A. Dauchess, L. K. Heung, R. L. Rabun, T. Motyka \\ Westinghouse Savannah River Company \\ Savannah River Site \\ Aiken, South Carolina 29808
}

\begin{abstract}
Hydrogen isotopes are separated from other gases by permeation through palladium and palladium-silver alloy diffusers in the Tritium Facilities at the US Department of Energy Savannah River Site (SRS). Diffusers have provided effective service for almost forty years. This paper is an overview of the operational experience with the various diffuser types that have been employed at SRS. Alternative technologies being developed at SRS for purifying hydrogen isotopes are also discussed.
\end{abstract}

\section{INTRODUCTION}

Hydrogen isotopes are commonly separated from other gases using palladium or palladium-25\% silver alloy permeation barriers. When at elevated temperature (typically $\sim 400^{\circ} \mathrm{C}$ ), these materials allow hydrogen isotopes to permeate through the barrier by solid-state diffusion while blocking all other gas species. This method is commonly used in laboratories to purify small quantities of hydrogen gas. When incorporated in a device including various gas inlet, outlet, pumping, temperature control, and other functions, this so-called diffuser can be used to purify significant amounts of all three hydrogen isotopes. Even though diffusers can successfully purify hydrogen isotopes from other gases, other types of purification methods using metal hydrides have been successfully developed both to improve diffuser performance and to replace diffusers.

DIFFUSER DESIGNS EMPLOYED AT SRS

Multistage Palladium Diffuser
The earliest diffusers used at Savannah River were single-stage, water cooled units designed specifically for the Tritium Facility by E.I. Du Pont de Nemours \& Co. After 1958 these units were redesigned to be a so-called "Multistage Palladium Diffuser", or MPD. Each stage of the Multistage Palladium Diffuser (Figure 1) consisted of one pure palladium diffuser tube wound in a coil supported by a ceramic core in its own flanged section, and the stages were connected by stainless steel jumpers. The palladium coil was electrically isolated from its shell (container), and the tube heated electrically by its own resistance by connecting the tube center to a power source and grounding each end of the tube. Each stage was contained by a water cooled stainless steel shell and cooling jacket, and the stages were connected using $\mathrm{O}$ ring seals. Water cooling of the shell reduced diffusion losses through the shell and prevented heat damage to the O-rings.

The Multistage Palladium Diffuser system was slow and hard to maintain. Repairs required disassembling a large portion of the stack to access a single stage. This exposed large, contaminated surfaces to the atmosphere, adding to environmental releases. The water cooling led to cases of localized corrosion or stress corrosion cracking. In addition, these diffusers had polymer O-ring seals which failed by becoming brittle during exposure to high temperature for excessive time. Water condensed from the process has been found in the MPD diffuser, which could have led to internal corrosion. The last of the MPD stages was taken out of service in 1985.

Resource Services Incorporated (RSI)

Diffusers manufactured by Resource Services Incorporated (RSI) diffusers came into 
service around 1983 (Fig. 2). These commercially available units use a $75 \%$ palladium $25 \%$ silver alloy for the diffusion coil (a coiled tube), which has both a higher hydrogen permeability and higher strength. They can be connected in multiple stages as required. The RSI diffusers have replaceable heaters and thermocouples. The coils have lasted for varying times between 4 months and 5.5 years. Most of these failures are believed to be caused by mercury present in this system (see below). Four RSI diffusers installed in a new tritium facility are expected to have a considerably longer service life because mercury is not present in the new system. Additionally, there were frequent failures of the stainless steel to palladiumsilver transition joint in earlier RSI units. Savannah River Site personnel worked with RSI to improve the braze design to prevent this type of failure.

The RSI diffuser consists of five coiled palladium-silver permeation tubes, mounted in parallel in a single chamber to reduce the pressure drop associated with high tube-side gas flows. The diffuser is heated by five replaceable cartridge heaters mounted in wells which are coaxial with the five permeation coils. Each heater is monitored by a thermocouple to detect failure of the heater. A failed heater cartridge can be replaced without shutting down the entire system. Also, operation can continue on the four remaining heaters until the fifth one is replaced. A sixth temperature control thermocouple is inserted in a well near the center of the cluster of permeation coils.

The RSI diffusers have many advantages compared to the old Multistage Palladium Diffuser units. They are not susceptible to cooling water corrosion and O-ring gasket leaks. The RSI design allows each stage to be repaired independently; the older diffuser had to be taken apart to be repaired. Because the RSI diffuser is commercially available, replacement parts are less expensive.

\section{Johnson Matthey Incorporated}

Two diffusers manufactured by Johnson Matthey, Inc. (JMI) were installed in the Tritium Facility diffuser system and tested as possible replacements for RSI diffusers. Having an alternate diffuser supplier was desirable because of cost, quality (braze joint failures), and delivery time concerns related to RSI diffusers.

The JMI diffuser incorporated several design improvements over the RSI diffuser (Fig. 3). The feed inlet tubing was coiled around the diffuser shell, under the insulation, to preheat the feed gas prior to entering the palladium coil. The JMI diffuser used only a single heater cartridge to heat the coils. Burnout of a heater cartridge was rare, and the single heater allows for better control of the palladium-silver coil temperature.

Tests at SRS revealed that the JMI diffuser was not equivalent to the RSI diffuser in separation performance. When operated at the same feed rate, the product rate of the JMI diffusers was about half that of RSI diffusers. Much of the product remained in the byproduct stream. When operated at the minimum byproduct rate, the JMI diffusers had about one-fourth the product rate of RSI diffusers and still did not produce acceptable byproduct. The JMI diffusers were designed for permeation from the shell to the coil rather than from the coil to the shell as in the RSI diffuser designs. The JMI design allows hydrogen isotopes in the feed to bypass the palladium coil and show up in the byproduct.

The two JMI diffusers were used in Tritium Facility for four years. During that time, no failures of the units occurred.

\section{Adolph Coors Company}

The Adolph Coors Company was contracted to manufacture a palladium diffuser similar to the RSI unit. This was done to develop another alternate commercial diffuser supplier. The Coors design incorporated the preheater and single heater design of the JMI diffuser but retained the coilto-shell product gas pathway of the RSI design (Fig. 4). In the Coors unit the close tolerance between the heater cartridge and its well (required to maximize the heat transfer efficiency) has caused warping of the well or heater cartridge. The heater is then wedged in the cartridge, rendering the unit useless. Adjusting the tolerance would allow the replacement of heater cartridges, while still providing for adequate heater performance. These diffusers were installed in 1993, and performance testing is underway. 


\section{Pretreatment Systems}

All gas to be fed to SRS diffuser systems is analyzed by mass spectrometer. This prevents a flammable mixture of hydrogen and oxygen from being fed to the diffuser. In an older process, the feed gas flows in turn through a hot uranium bed, a zeolite bed, and finally through a sacrificial palladium bed. The uranium bed reduces moisture in the feed stream, and must be discarded after the uranium is completely oxidized. This bed is used when the feed gas contains an excessive amount of moisture. The zeolite bed also removes moisture at roughly ambient temperature. Finally, the sacrificial palladium bed contains palladium supported by an alumina substrate, to trap any impurities that could react with the diffuser tube alloy. A new tritium process uses only the sacrificial palladium bed to treat the diffuser feed, because this process has much less moisture than the older process.

\section{DIFFUSER FAILURE MODES}

Review of the history of diffusers in the Tritium Facilities at the Savannah River Site reveals several recurring failure modes. The palladium or palladium-silver alloy coils failed by attack from liquid mercury used in diffusion pumps in the older processes, and by stearn attack at grain boundaries [1]. (Liquid metal embrittlement [2] and liquid metal corrosion [3] are well known failure modes of metals and alloys.) The palladium to stainless steel braze joint has been a recurring mode of failure of diffusers, especially in the past fifteen to twenty years. Thermocouples and heater elements fail and are replaced routinely. Corrosion or stress corrosion cracking by cooling water was a failure mode of older Multiple Palladium Diffuser. This type also had polymer O-rings that were replaced regularly. The ancillary pumps and valves used with diffusers also frequently failed by localized aqueous or mercury corrosion or stress corrosion cracking.

Steam attack is caused by hydrogen isotopes reacting with excessive oxygen, in the palladium or in the process stream, to form molecular water at grain boundaries. The water molecules accumulate, and form steam cavities that open the boundaries and lead to failure. Steam attack is a recognized failure mechanism of palladium diffusers [1], and also occurs in copper. Water vapor in the process stream can cause steam attack, but is not required for this reaction to occur. If sufficient oxygen is either in the inlet stream or in oxide inclusions in the palladium, enough hydrogen can permeate the diffuser coil during operation to cause the attack.

Palladium diffuser coils have not failed at SRS by hydride formation during inadvertent cooling of the diffuser. Assuming occasional inadvertent cooling of the palladium, this failure mode might be anticipated. Heaters, heater controllers, and thermocouples have all failed on occasion, but apparently insufficient hydrogen isotopes were present in the palladium coils to cause hydriding at the lowest temperatures reached. Multiple thermocouples are normally used, so that the control function of a failed thermocouple can be replaced by a backup. Eventually all must be replaced during routine maintenance.

\section{ALTERNATIVE HYDROGEN PURIFICATION TECHINOLOGIES}

Alternatives to palladium or palladiumsilver diffusers have been developed at the Savannah River Site over the past ten years, utilizing metal hydrides to separate hydrogen isotopes from inert gases $[3,4]$. Two of the early alternatives relied on palladium supported on Kieselguhr (calcined diatomaceous earth) as the absorbing material. While these processes have been effective, their ability to achieve extremely low levels of hydrogen in the byproduct is somewhat less than that of a series of diffusers due to the relatively high equilibrium pressure of hydrogen over palladium even at low temperatures. One of these processes, termed the Primary Separator, is in use in a new facility just ahead of the diffusers. This significantly reduces the load on the diffusers and improves their performance. Other metal hydride separator systems with lower equilibrium hydrogen pressures are being evaluated, including zirconium-iron alloys and titanium sponge.

\section{Cryogenic Still Feed Pump/Purifier}

The cryogenic still feed pump/purifier is a bed containing palladium supported on Kieselguhr $(\mathrm{Pd} / \mathrm{k})$ that pumps and purifies hydrogen isotopes to be fed to a cryogenic 
distillation column. Kieselguhr is a highly porous diatomite and is used because it has a high surface area, $8 \mathrm{~m}^{3} / \mathrm{g}$, and is hydrophobic. The $\mathrm{Pd} / \mathrm{k}$ contains $50 \%$ palladium by weight. The unit consists of three beds connected in parallel (Fig. 5). Each vessel is heated by electrical heaters in heater wells, and cooled by Freon ${ }^{\mathrm{TM}}$ flowing through cooling coils wrapped on the outside of the vessel wall. A secondary vessel is used as a vacuum jacket for thermal insulation and containment [4].

The feed pump/purifier operates in three steps. First, the gas to be purified is brought to the cooled beds, and the hydrogen isotopes are absorbed by the palladium. Next, the remaining gas. (not hydrogen) is pumped away. Finally, the beds are heated and the purified hydrogen isotopes desorb from the palladium and are recovered. The absorption and non-hydrogen pump-off steps can be repeated if the feed gas contains a high level of inert gases.

\section{Primary Separator (Flow-through Bed)}

The flow-through bed is a semicontinuous version of the feed pump/purifier discussed above. The flow-through bed was designed to provide most of the hydrogen purification in a new tritium facility, and thereby reduce the load on the palladiumsilver tube diffusers. The diffusers function is to remove remaining low levels of hydrogen from the gas passing through the flowthrough bed.

The flow-through beds are columns filled with palladium supported on Kieselguhr (Fig. 6), the same as that used in the still feed pump/purifier. Each column is heated and cooled by hot and cold nitrogen circulating in a jacket. Thermocouples in wells are placed along the length of the columns for the detection of the absorption front. In one application three U-shaped (to reduce space) columns are used to form one unit. The first two columns are connected in parallel, while the third is in series.

A typical operation cycle consists of an absorption step and a desorption step. Gas containing hydrogen isotopes and impurities flows through the cooled columns, the hydrogen isotopes are absorbed by the palladium, and the impurities are pumped through the columns. When the columns are full, they are heated and the purified hydrogen isotopes are recovered.

A flow-through bed has been successfully operated since January 1994 in a new tritium facility. Hydrogen isotope and helium purities have been better than expected.

\section{Advanced Hydrogen Isotope Purifier}

The cryogenic still feed pump/purifier and the flow-through bed discussed above are both based on palladium supported on Kieselguhr. Both processes are very efficient at removing most of the hydrogen (better than 99.5\%) from the feed and producing high purity hydrogen. However, they can only reduce the hydrogen level in the by-product stream to about $0.1 \%$. A diffuser is required to further reduce the hydrogen level to less than $0.05 \%$. Further reduction of tritium to part per million levels would be desirable. It is impractical for diffusers to achieve part per million levels of hydrogen in inert streams. An alternative process is being sought that can both replace the function of a diffuser and reduce the hydrogen in an inert stream down to part per million levels.

Neodymium-cobalt (NdCo3) was selected from a series of low pressure metal hydrides for bench scale test to separate hydrogen from helium. The tests consisted of processing batches of hydrogen and helium gas mixtures through a column filled with $\mathrm{NdCo} 3$ powder. The results show that a $50 \%$ hydrogen in helium feed stream is purified to a helium stream of purity greater than $99.98 \%(0.02 \%$ hydrogen), which matches the purity of a diffuser, although it cannot achieve part per million levels [7].

The ability of SAES St $198^{\mathrm{TM}}$ ( $\mathrm{ZrFe}$ ) to remove low levels of hydrogen from a nitrogen stream was examined. Nitrogen containing about 100 part per million deuterium was passed through a heated packed bed of St $198^{\mathrm{TM}}$ granules, and the deuterium level was reduced to less than the detection limit of the mass spectrometry of 0.5 part per million. The results demonstrated that St $198^{\mathrm{TM}}$ can strip hydrogen from nitrogen or inert streams down to the part per million level [8]. 
Titanium is known to absorb hydrogen at high temperatures and the resulting hydride has a very low equilibrium pressure $\left(10^{-14}\right.$ $\mathrm{Pa})$, thus having the potential to effectively remove hydrogen isotopes from inert gas streams. Tests showed that titanium sponge absorbs hydrogen readily at $200^{\circ} \mathrm{C}$ after it has been activated at $500^{\circ} \mathrm{C}$ under vacuum. It also absorbs hydrogen readily at room temperature if the activation temperature is increased to $700^{\circ} \mathrm{C}$. Titanium has a very high capacity for hydrogen, up to $4 \%$ by weight. The capacity is reversible if the hydride is regenerated at $700{ }^{\circ} \mathrm{C}$ under a vacuum of 1 Torr (133 Pa) or better. Half of its capacity $(2 \%)$ is reversible if the regeneration temperature is decreased to $500^{\circ} \mathrm{C}$. These data indicate that when kept at about $200^{\circ} \mathrm{C}$, titanium should be able to strip hydrogen from an inert gas stream.

\section{CONCLUSIONS}

Modern commercially available diffusers can reliably purify hydrogen isotopes from process gases. These devices can be arranged to achieve the desired system capacity. Many palladium-silver alloy tube failures at SRS in diffusers were related to either mercury or steam attack. New processes, based on metal hydrides, show promise to achieve hydrogen isotope purification levels rivaling or exceeding that of diffusers.

\section{REFERENCES}

1) Encyclopedia of Chemical Technology, Third Edition, Vol. 18, p 248. John Wiley \& Sons, New York (1982).

2) M.H. Kamdar. Liquid Metal Embrittlement, in Metals Handbook, gth $^{\text {Edition, Vol. 11: }}$ Failure Analysis and Prevention, American Society for Metals, Metals Park, Ohio, p 225 (1986).

3) P.F. Tortorelli. Fundamentals of HighTemperature Corrosion in Liquid Metals., in Metals Handbook, gth Edition, Vol. 13: Corrosion, ASM International, Materials Park, Ohio, p 56 (1987).

4) M. S. Ortman, L. K. Heung, A. Nobile and R. L. Rabun III. Tritium Processing at the
Savannah River Site: Present and Future J. Vac. Sci. Technol. A8 (3) (May/June, 1990).

5) A. Nobile, Jr. Experience Using Metal Hydrides for Processing Tritium,. Fusion Technology $\underline{20}$ (September 1991).

6) T. Motyka. The Replacement Tritium Facility, Fusion Technology, 21 (2) (March 1992).

7) I. A. Fisher. Selection of a Hydride Former for the Separation of Hydrogen Isotopes from Inert Gases, Journal of Less-Common Metals, 172174 (September 1991).

8) A. Nobile, Jr. Removal of Deuterium from Flowing Nitrogen by SAES ST 198, USDOE Report WSRC-TR-92-603, Savannah River Site, Aiken, SC (December1992). 


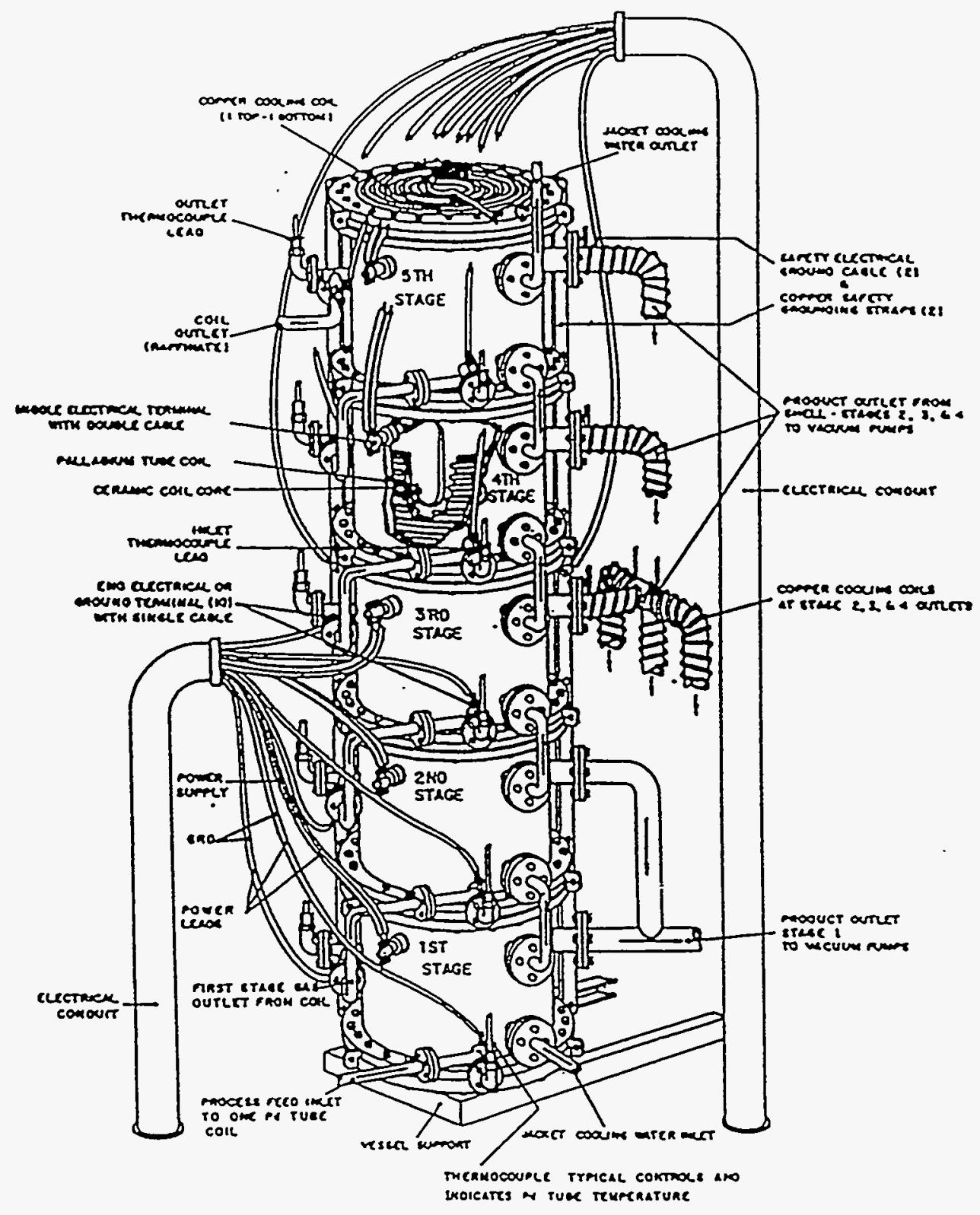

Figure 1. Multistage Palladium Diffuser 


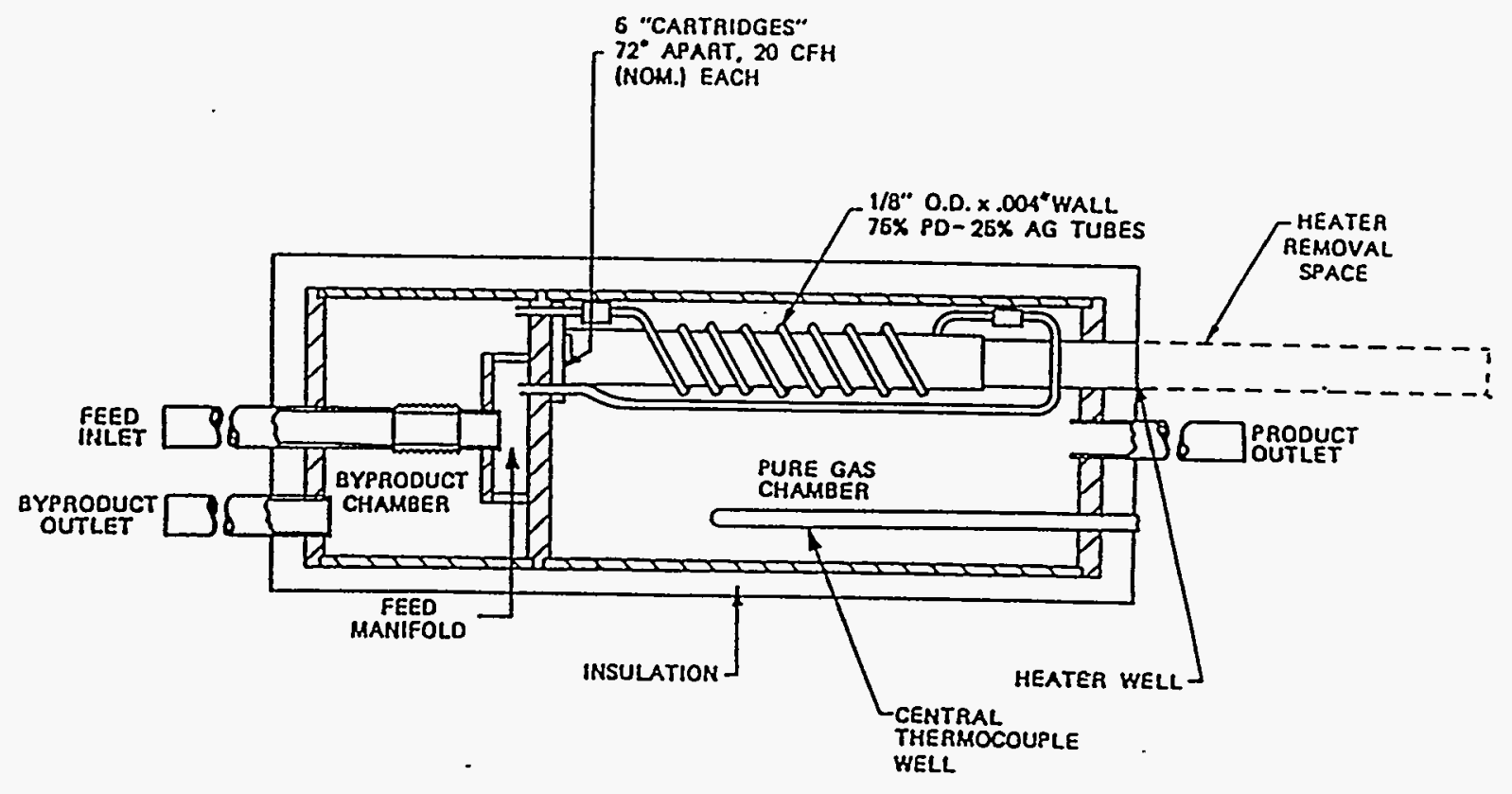

Figure 2. Single Stage RSI Diffuser 


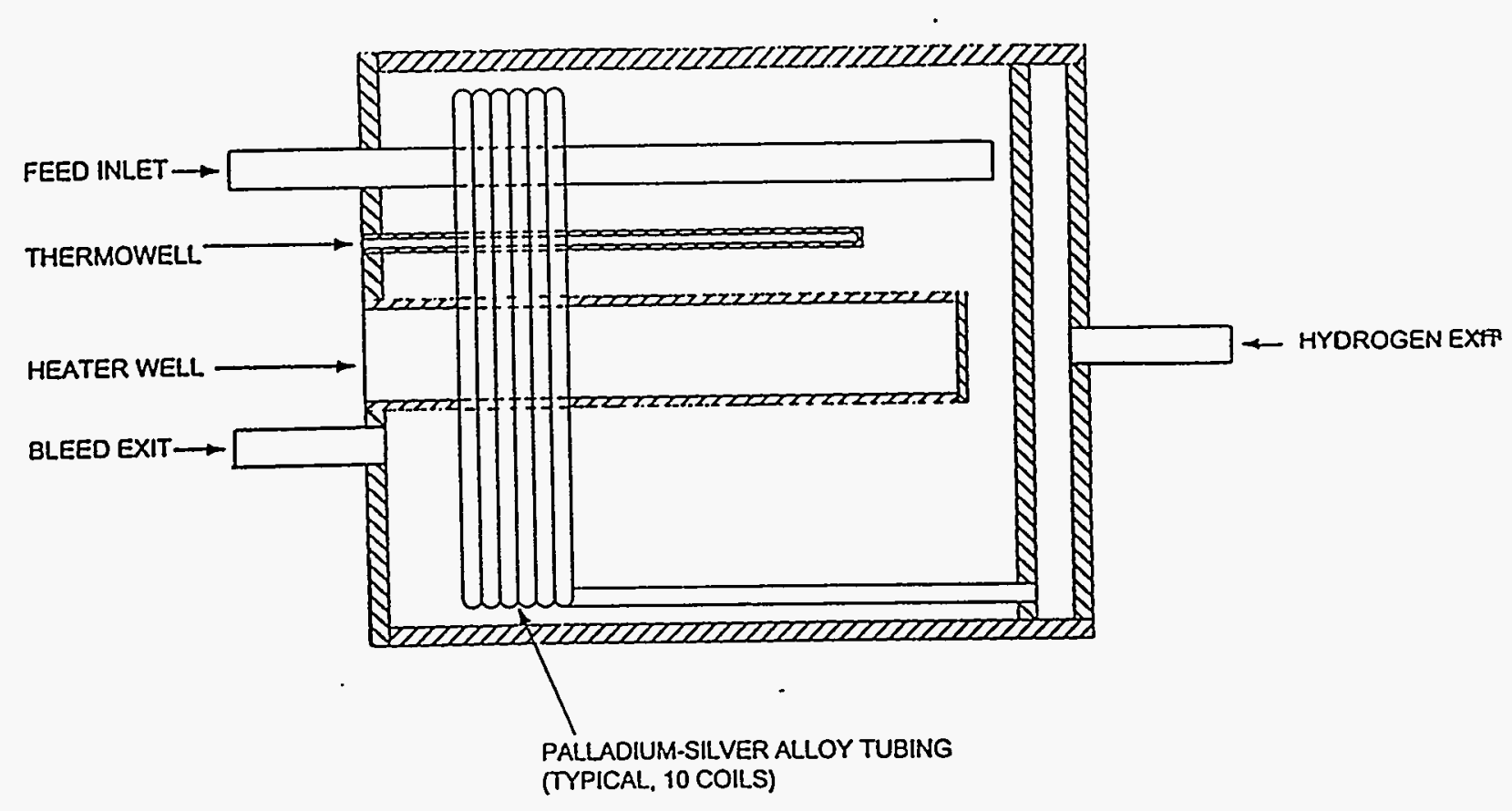

Figure 3. Johnson Matthey, Incorporated (JMI) Diffuser 


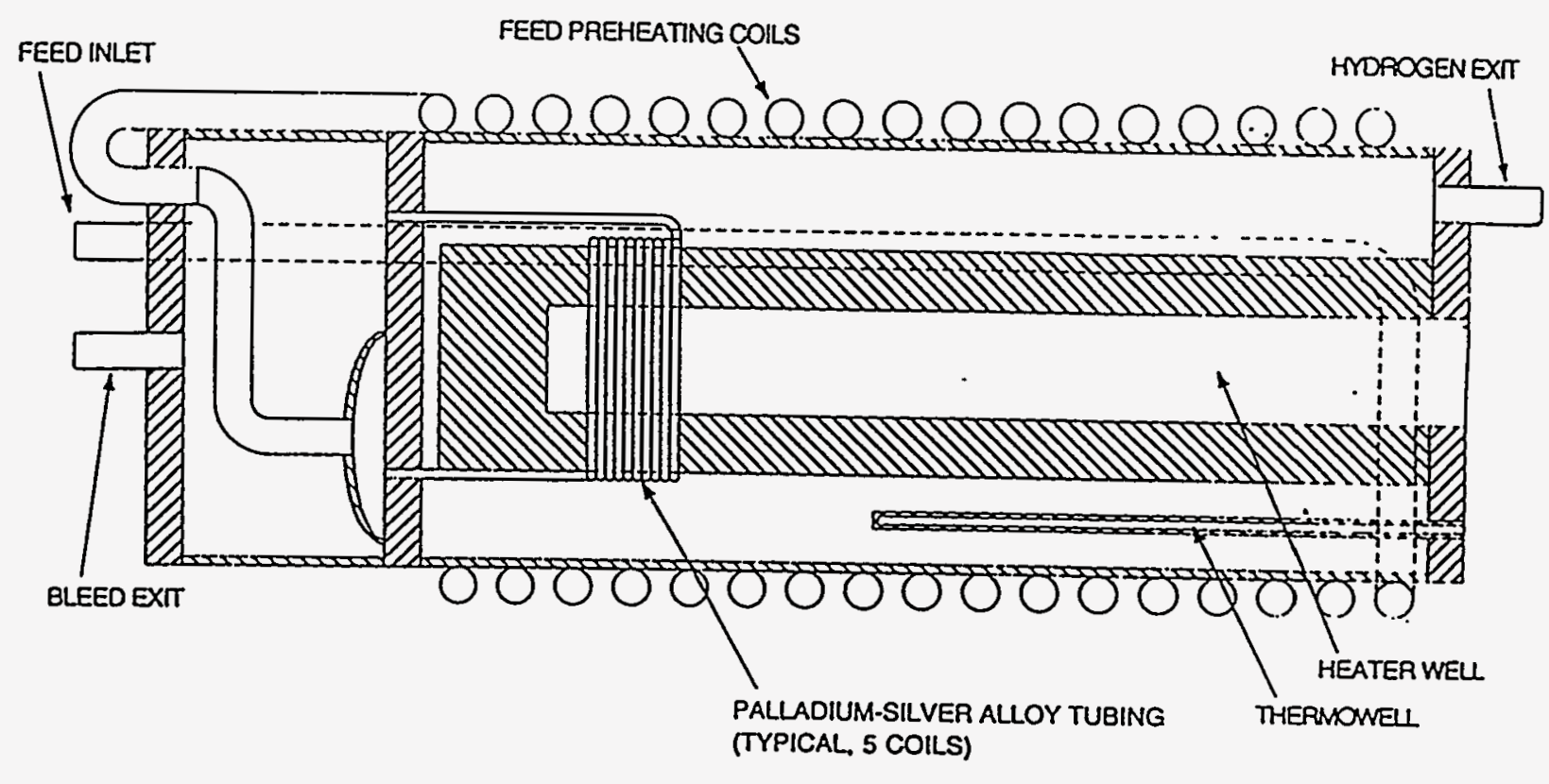

Figure 4. Adolph Coors Company Diffuser 


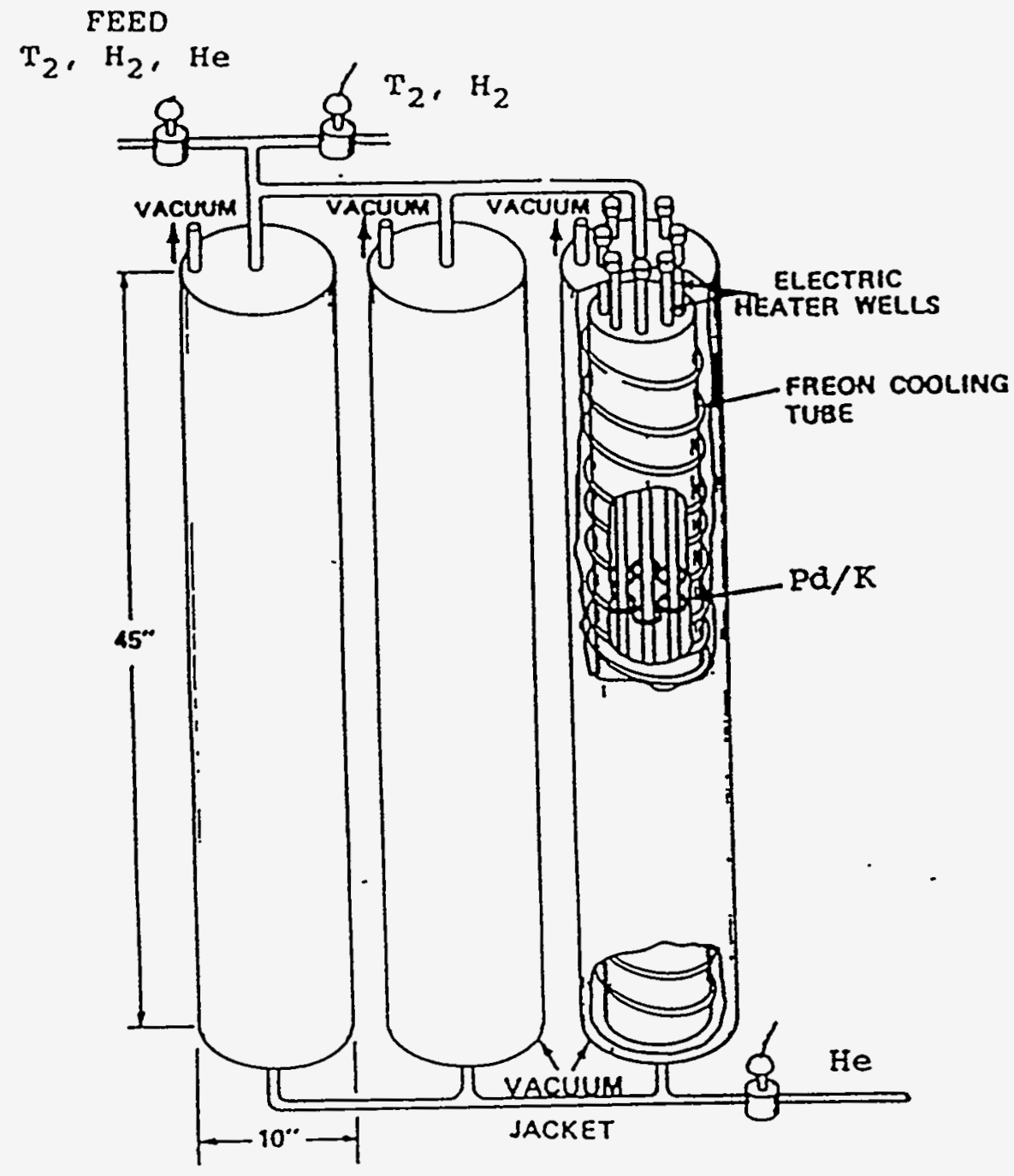

Figure 5. Still Feed Pump Separator - Design 


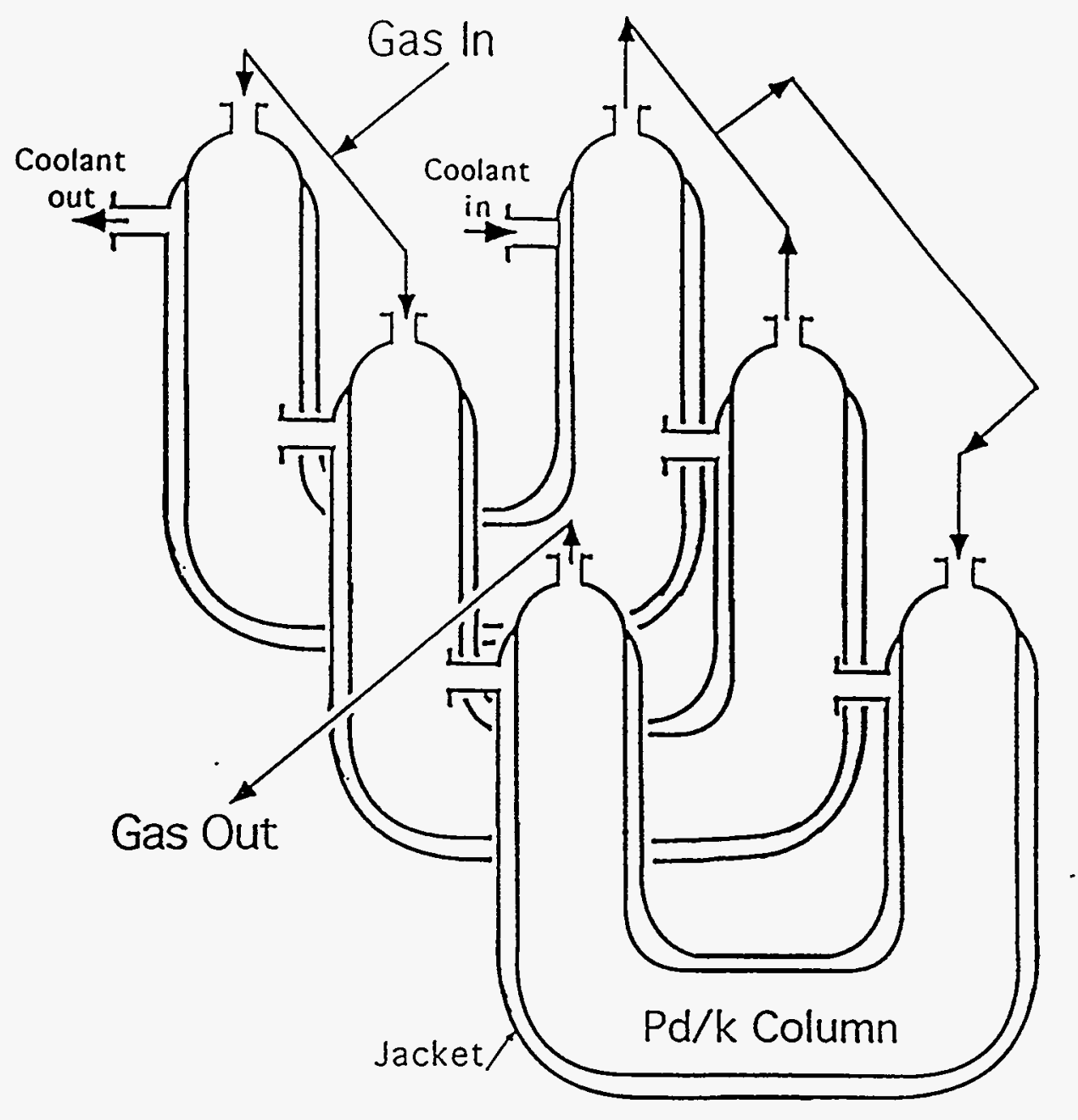

Figure 6. Primary Separator (Flow Through Bed) 


\title{
Experience with Palladium Diffusers in Tritium Processing
}

\author{
by \\ T. Motyka \\ Westinghouse Savannah River Company \\ Savannah River Site \\ Aiken, South Carolina 29808 \\ E. A Clark \\ D. A. Dauchess \\ L K. Houng \\ R. L Rabum
}

A document prepared for FIFTH TOPICAL MEETING ON TRITIUM TECHNOLOGY IN FISSION, FUSION, AND ISTOPIC APPLICATIONS at Lake Maggiore from 05/28/95 - 06/03/95.

DOE Contract No. DE-AC09-89SR18035

This paper was prepared in connection with work done under the above contract number with the U.S.

Department of Energy. By acceptance of this paper, the publisher and/or recipient acknowledges the U.S. Government's right to retain a nonexclusive, royalty-free license in and to any copyright covering this paper, along with the right to reproduce and to authorize others to reproduce all or part of the copyrighted paper. 